\title{
Freezing of water droplets colliding with kaolinite particles
}

\author{
E. A. Svensson ${ }^{1}$, C. Delval ${ }^{2,3}$, P. von Hessberg ${ }^{2}$, M. S. Johnson ${ }^{2}$, and J. B. C. Pettersson ${ }^{1}$ \\ ${ }^{1}$ Department of Chemistry, Atmospheric Science, University of Gothenburg, 41296 Gothenburg, Sweden \\ ${ }^{2}$ Copenhagen Centre for Atmospheric Research, Department of Chemistry, University of Copenhagen, Universitetsparken 5, \\ 2100 København Ø, Denmark \\ ${ }^{3}$ EPFL STI IMT LOA, Station 17, 1015 Lausanne, Switzerland
}

Received: 19 November 2008 - Published in Atmos. Chem. Phys. Discuss.: 27 January 2009

Revised: 8 June 2009 - Accepted: 16 June 2009 - Published: 3 July 2009

\begin{abstract}
Contact freezing of single supercooled water droplets colliding with kaolinite dust particles has been investigated. The experiments were performed with droplets levitated in an electrodynamic balance at temperatures from 240 to $268 \mathrm{~K}$. Under relatively dry conditions (when no water vapor was added) freezing was observed to occur below $249 \mathrm{~K}$, while a freezing threshold of $267 \mathrm{~K}$ was observed when water vapor was added to the air in the chamber.

The effect of relative humidity is attributed to an influence on the contact freezing process for the kaolinite-water droplet system, and it is not related to the lifetime of the droplets in the electrodynamic balance. Freezing probabilities per collision were derived assuming that collisions at the lowest temperature employed had a probability of unity. Mechanisms for contact freezing are briefly discussed.
\end{abstract}

\section{Introduction}

At temperatures higher than the threshold for homogeneous nucleation, a solid particle is required for ice nucleation to take place. In this heterogeneous nucleation process, the solid surface helps align the water molecules in an ice-like structure (Cantrell and Heymsfield, 2005). Hence, heterogeneous freezing temperatures depend on the surface properties of the solid substrate. Additionally, factors such as the surface area of the solid particle are important. At the moment, there is no unifying theoretical framework to describe heterogeneous freezing of water.

It is known that heterogeneous freezing occurs at higher temperatures when a solid particle collides with the droplet compared to when the particle is completely immersed inside the droplet (Pruppacher and Klett, 1998). This has been

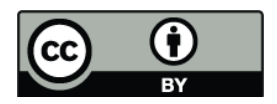

Correspondence to: J. B. C. Pettersson (janp@chem.gu.se) confirmed for mineral dust (Pitter and Pruppacher, 1973) and pollen (von Blohn et al., 2005), with a possible exception for soot particles (Diehl and Mitra, 1998). Kaolinite $\left(\mathrm{Al}_{2} \mathrm{Si}_{2} \mathrm{O}_{5}(\mathrm{OH})_{4}\right)$ is built up from alternating layers of silica and aluminum hydroxide (Miller et al., 2007) and it is known to make an important contribution to the atmospheric aerosol in several parts of the world (e.g. Singer et al., 2004; Drab et al., 2002; Shi et al., 2005). Kaolinite particles are known to be moderately efficient cloud condensation nuclei (Gibson et al., 2007). Salam et al. (2006) examined heterogeneous ice nucleation on kaolinite particles in the deposition mode involving the direct transition of water vapor into ice. The particles were activated as ice nuclei at $251 \mathrm{~K}$ and $123 \%$ relative humidity with respect to ice. In the immersion freezing mode previous studies have been performed using a wind tunnel (Pitter and Pruppacher, 1973) and an acoustic levitator (Ettner et al., 2004). Pitter and Pruppacher (1973) observed freezing of water droplets with kaolinite immersions in a temperature range from 243 to $259 \mathrm{~K}$. They also studied contact freezing with the same components and showed that in this mode the freezing temperatures were substantially higher, $266 \mathrm{~K}$ to $268 \mathrm{~K}$.

In the present study, we reexamine contact freezing between water and kaolinite dust particles in an electrodynamic balance (EDB). Experiments have been performed in the temperature range from 240 to $268 \mathrm{~K}$, and the effects of temperature and relative humidity on the efficiency of contact freezing were investigated.

\section{Experimental}

The experiments were performed in an EDB setup described in detail elsewhere (Svensson et al., 2009). Briefly, a doublering EDB (Davis et al., 1990) is situated in a temperature controlled chamber. A HeNe-laser operating at $633 \mathrm{~nm}$ illuminates the central region of the EBD and two cameras

Published by Copernicus Publications on behalf of the European Geosciences Union. 


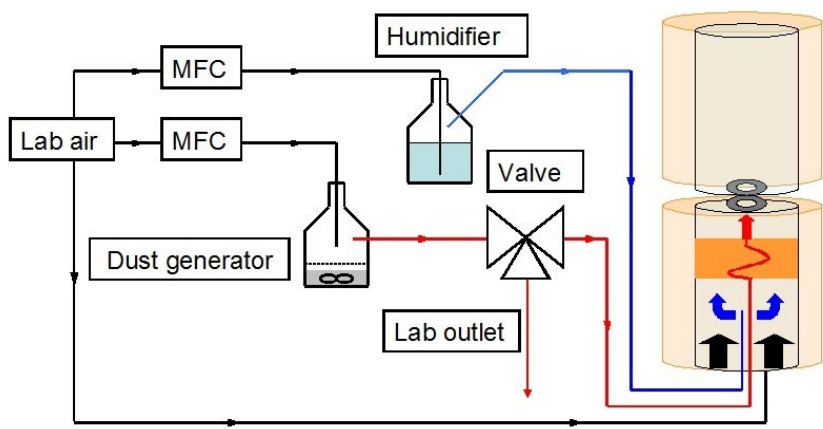

Fig. 1. Schematic view of the experimental setup. Black lines and arrows correspond to clean dry air, red lines/arrows to kaolinite aerosol and blue lines/arrows to humidified air.

observe the droplet. One camera records the ordinary picture of the droplet and the surroundings and the other records the light scattering pattern. The droplet size can be estimated by counting the fringes and comparing with predictions from Mie theory (Mishchenko et al., 2002). Droplets were produced using a syringe with an electrically charged needle or a piezoelectric droplet generator. This setup has proven its ability to reproduce homogeneous freezing rates for pure water (Svensson et al., 2009).

For the studies presented here two important features were added, which are shown schematically in Fig. 1. In order to be able to operate at high temperatures $(268 \mathrm{~K})$ the relative humidity (RH) had to be high. Otherwise, droplets would have evaporated within a few seconds. There was an air flow in thermal equilibrium with the chamber walls running through the chamber during the experiments. Due to a pressure drop in the circuit, it was not possible to humidify this air efficiently. A minor flow of humid air was instead injected directly into the chamber. This humid air mixed with the upward flow of dry air in thermal equilibrium with the walls about $50 \mathrm{~mm}$ below the EDB rings, which increased the RH substantially. The additional flow of humid air was zero at $240-251 \mathrm{~K}$, intermediate at $258 \mathrm{~K}$ and high at $263-268 \mathrm{~K}$. Since the mixing took place inside the chamber, the RH could not be explicitly known. In all cases in this study droplets evaporated, which implies that the water vapor pressure near the droplets was below saturation. At $267 \mathrm{~K}$ a droplet with an initial diameter of $50 \mu \mathrm{m}$ typically stayed large enough to be observed for about $30 \mathrm{~s}$.

Injecting warm and humid air into the chamber changed the temperature in the chamber. The temperature at the droplet position between the rings was calibrated using a small Pt-100 sensor. At a setpoint temperature of $267 \mathrm{~K}$, the temperature at the droplet position was about $1 \mathrm{~K}$ higher than the copper blocks.

An aerosol generator was also constructed. A plastic bottle with kaolinite powder (Fluka, purum, natural, product number 13584) and a magnetic stirrer was used to dispense dust.
Suspension and settling was assumed to result in an equilibrium concentration of kaolinite particles in the air inside the bottle. The air flow through the bottle was regulated by a mass flow controller (MFC) and was running continuously during an experiment. A valve directed the aerosol flow either out through the lab ventilation or into the experiment chamber. The flow was cooled to chamber wall temperature by passing through a piece of copper in contact with the temperature controlled chamber walls. The particle inlet was located $10 \mathrm{~mm}$ below the electrode rings. The particles were thus introduced close to the droplet position, while the humid air inlet was $50 \mathrm{~mm}$ from the droplet. The conditions in the vicinity of the droplet are not expected to be neither cold nor humid enough to cause deposition ice nucleation onto the kaolinite particles (Salam et al., 2006). Considering the proximity of the particle inlet to the droplet and the distance between the particle and humid air inlets, it appears unlikely that super-saturated conditions should transiently occur near the particle inlet. However, we had no means to investigate this experimentally and have not done so by calculations.

The particle flow into the chamber was switched off most of the time. As a droplet was trapped, the flow was turned on until the droplet was frozen or had evaporated. Before the next droplet was injected, the chamber was flushed with air. At all temperatures droplets were also trapped without injecting dust particles and on these occasions no freezing was observed.

The copper cooling device was electrically grounded by contact with the chamber walls. This modified the electrical field in which the droplet was trapped, which changed the movement of the droplet in the trap. With this arrangement, superposing a DC voltage between the rings had little effect on droplet position and was not used during the experiments. The spring-point phenomenon (Davis et al., 1990) was not observed here. As droplets evaporated, they tended to move upwards and if the $\mathrm{AC}$ amplitude was decreased the droplets exited to the sides rather than downwards as in ordinary EDBs.

The aerosol size distribution between the rings was measured between the experimental runs using an aerosol spectrometer (Grimm, Dustmonitor model 1.108) and the number concentration was measured with a condensation particle counter (CPC) (TSI model 3010). A typical particle size distribution measured with the aerosol spectrometer at the droplet position is shown in Fig. 2. The size distribution was broad with a substantial fraction of submicron particles and the concentration dropped rapidly for particle sizes above $3 \mu \mathrm{m}$. Concentrations measured with the CPC at the droplet position varied with the flow through the dust dispensing bottle. Typically, the number concentration measured with the $\mathrm{CPC}$ was $200 \mathrm{~cm}^{-3}$. The number concentration was stable within $20 \%$. Rise times from turning on the valve to steady state concentrations were typically $6 \mathrm{~s}$, and the measured values were compensated for this effect. The measured concentrations are however not expected to be representative for 


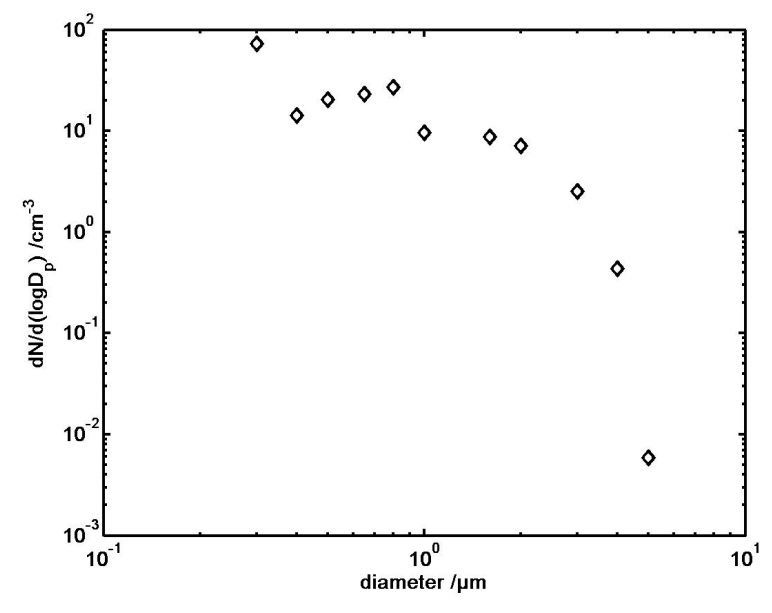

Fig. 2. Number size distribution of the kaolinite dust particles measured with an aerosol spectrometer.

the concentration in the vicinity of the droplet during freezing experiments. This is due to two reasons: i) The particles came out from the outlet of the particle flow cooler following the air stream. The dispersion and mixing of this air stream with the surrounding air caused a spatial variation in the particle concentrations. ii) When measuring the particle concentrations with either the CPC or the Dustmonitor, the presence of a tube sucking air disturbs the flow of particles at the droplet position. In addition, the probability for particle-droplet collisions should depend on the flow conditions around the droplets during the experiments, which introduces a dependence on particle size. The oscillation of the droplets described earlier caused the droplets to sweep a larger area than their cross-sections. Hence, we do not expect the collision frequency to be strongly dependent on droplet diameter. None of these effects are expected to change significantly within the limited temperature and relative humidity ranges used in this study, and they have not been directly accounted for. Instead, the probability of collision with a droplet per time unit were assumed to be proportional to the observed particle number concentrations.

\section{Results}

Contact freezing of water droplets colliding with kaolinite dust particles has been investigated at temperatures from 240 to $268 \mathrm{~K}$ and with different relative humidities. The initial droplet size was typically about $60 \mu \mathrm{m}$. In total 159 droplets were analyzed in this study, and the results from the experiments are summarized in Table 1. Experiments were carried out with different kaolinite particle air flows, PF, in order to change the particle number concentrations. Several droplets lost so much of their volume while staying liquid that we were unable to determine whether they did freeze. These
Table 1. Summary of the experiments. $T$ is the air temperature between the rings, $N_{\text {tot }}$ is the number of particles studied at each temperature, $N_{\text {frozen }}$ is the number of frozen particles, and $P F$ is the kaolinite particle air flow. The means and standard deviations of the freezing times are given in the fifth and sixth column respectively. Only the droplets that were observed freezing are used in the two last columns.

\begin{tabular}{rrrrrr}
\hline$T / \mathrm{K}$ & $N_{\text {tot }}$ & $P F / \mathrm{min}^{-1}$ & $N_{\text {frozen }} / N_{\text {tot }}$ & $\bar{t}_{f} / s$ & $\mathrm{std}\left(t_{f}\right) / \mathrm{s}$ \\
\hline 240 & 9 & 0.43 & 1 & 38 & 25 \\
242 & 3 & 0.43 & 1 & 19 & 15 \\
243 & 7 & 0.43 & 1 & 43 & 21 \\
244 & 4 & 0.43 & 0.75 & 20 & 10 \\
246 & 10 & 0.43 & 0.5 & 57 & 18 \\
247 & 10 & 0.43 & 0.3 & 29 & 16 \\
249 & 3 & 0.43 & 0 & & \\
251 & 4 & 0.43 & 0 & & \\
258 & 10 & 0.83 & 0.5 & 20 & 19 \\
263 & 5 & 0.83 & 1 & 12 & 5.0 \\
266 & 29 & 0.83 & 0.79 & 18 & 7.6 \\
267 & 4 & 0.83 & 0 & & \\
267 & 8 & 1.25 & 1 & 11 & 3.0 \\
268 & 7 & 0.83 & 0 & & \\
\hline
\end{tabular}

droplets will be treated as if they did not freeze at all. The last column in the table gives the ratio between the number of frozen droplets and the total number of droplets at each temperature. The results in Table 1 show that for a given flow of kaolinite particles and a given humidity, the freezing probability decreased with increasing temperature. The particle-droplet collisions thus became less efficient in inducing freezing at high temperatures. The decrease in freezing probability could be partially counter-acted by increasing kaolinite particle concentration and thereby the collision rate. The relative humidity was mainly increased in order to maintain levitated droplets for a longer time in the EDB at high temperatures where the evaporation rate is high. However, an interesting result is that the freezing probability also appears to increase with increasing humidity.

To study the collision efficiency in greater detail, the results were corrected for differences in the number of collisions experienced by each droplet. For each droplet, the number of collisions before freezing was estimated by

$N_{\text {coll }}=F \times t_{f} \times C$,

where $F$ is a conversion factor derived assuming that all droplets freeze on the first collision at $240 \mathrm{~K}, t_{f}$ is the time before freezing and $C$ is the particle number concentration measured by the CPC. Hence, in cases where all droplets freeze, the freezing efficiency, i.e. the number of freezing events per collision, can be estimated by,

$E=\frac{N_{\text {droplets }}}{\sum N_{\text {coll }}}=\frac{N_{\text {droplets }}}{F \times \sum t_{f} \times C}$, 


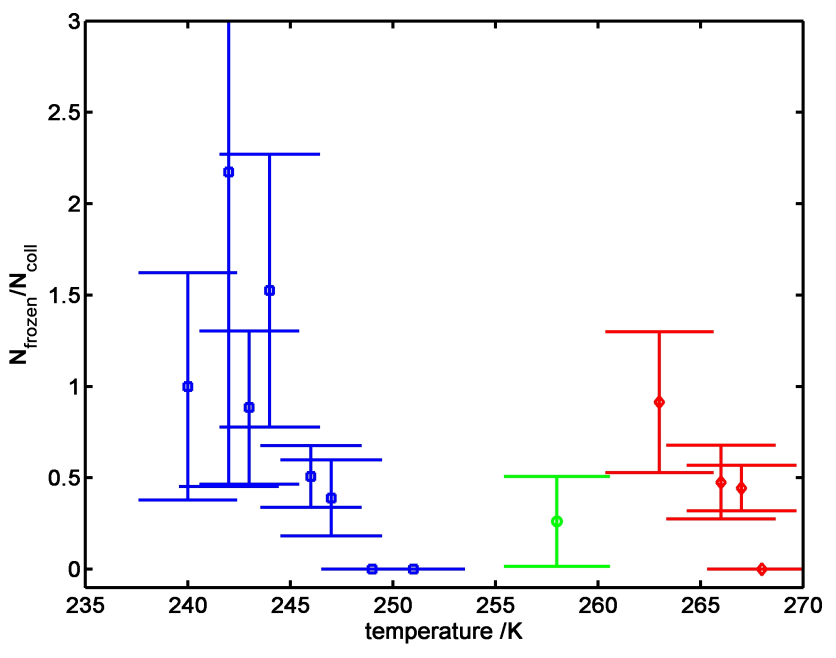

Fig. 3. Estimated number of freezing events per collision. Error bars are the standard deviation of the entity $N_{\text {frozen }}^{3} \times t_{f} /\left(F \times\left(\sum_{\text {frozen }} t_{f}\right)^{2} \times C \times N_{\text {total }}\right)$ whose mean is the $E$ of Eq. (3). Blue symbols represent experiments under dry conditions, green symbols intermediate flow of humid air, and red symbols high flow of humid air.

where $N_{\text {droplets }}$ is the number of droplets at each temperature. Because freezing is assumed to happen by the first collision at $240 \mathrm{~K}, F$ is calculated by setting $E$ to 1 for the droplets at this temperature. However, at many temperatures not all droplets froze. We can estimate the number of collisions experienced by an unfrozen droplet with the average of the numbers of collisions for the frozen droplets at the same temperature. Using the number of frozen droplets, $N_{\text {frozen }}$ and the total number of droplets, $N_{\text {total }}$, the freezing efficiency becomes

$E=\frac{N_{\text {frozen }}}{F \times \sum_{\text {frozen }} t_{f} \times C} \times \frac{N_{\text {frozen }}}{N_{\text {total }}}$

Effects of droplet or particle size were not included in this analysis. The freezing efficiencies are plotted in Fig. 3. The data clearly illustrate that under dry conditions, the freezing efficiency decreases when going from 240 to $251 \mathrm{~K}$. The decrease is not an effect of a shorter residence time in the EDB at higher temperatures since the droplet lifetime has been accounted for in Eq. (3). At temperatures where only a few droplets were investigated, the uncertainties become large. However, no $E$ value is above 1 within uncertainty. The results in Fig. 3 also show that the humidity has an important effect on the freezing probability. For the highest flow of humid air, the freezing probability is high at $263 \mathrm{~K}$, and then again drops as the temperature is further increased. The numbers of frozen droplets are generally too low to make any general conclusions about the statistical distributions.

\section{Discussion}

There exist pronounced differences between the major ice formation mechanisms involving kaolinite (as well as other clays and minerals). Several earlier studies (Mason and Maybank, 1958; Roberts and Hallett, 1968; Shaller and Fukuta, 1979; Bailey and Hallett, 2002) demonstrated that the threshold temperature for ice nucleation by deposition freezing on kaolinite is about $253 \mathrm{~K}$. For immersion mode freezing, an onset temperature of $259 \mathrm{~K}$ has been reported (Pitter and Pruppacher, 1973). The results presented here confirm that contact freezing is the most efficient ice nucleation process involving kaolinite particles, with freezing temperatures being observed up to $267 \mathrm{~K}$. In previous work Pitter and Pruppacher (1973) studied contact freezing of water drops with kaolinite and montmorillonite particles. Supercooled water droplets with a diameter of $650 \mu \mathrm{m}$ were suspended in a vertical wind tunnel at temperatures from 243 to $273 \mathrm{~K}$ and in a relatively dry air stream, and the $\mathrm{RH}$ varied from $60 \%$ to ice saturation depending on operating conditions. The size of the clay particles varied from about 0.1 to $30 \mu \mathrm{m}$ in diameter and had a mode between 1 and $2 \mu \mathrm{m}$. Kaolinite and montmorillonite were concluded to behave similarly as ice-forming nuclei and induce freezing at temperatures up to $270 \mathrm{~K}$. For kaolinite, contact freezing was observed below $269 \mathrm{~K}$ and the freezing probability increased to $100 \%$ as the temperature decreased to $256 \mathrm{~K}$. It was estimated that the water drops captured several thousand particles during the time the clay particles passed the drops. The results from the present experiments at the higher temperatures are consistent with the previous results by Pitter and Pruppacher (1973). Assuming a collision efficiency of unity at $240 \mathrm{~K}$, we conclude that one or a few collisions are usually sufficient to induce contact freezing under the conditions employed here. We can not directly prove that a single collision at $240 \mathrm{~K}$ indeed is sufficient to induce contact freezing, and the direct proof will have to await further studies using fast cameras with micrometer resolution. However, the assumption appears reasonable considering that $240 \mathrm{~K}$ is close to the temperature where homogeneous freezing of water occurs and far below the threshold temperature for immersion freezing induced by kaolinite.

A few attempts have been made to explain the mechanism(s) behind contact freezing, but the matter remains unresolved. Cooper (1974) suggested a mechanism by which an ice embryo formed on the surface of an ice nucleus was able to induce freezing upon contact with a supercooled water drop. Fukuta (1975) suggested that contact nucleation is associated with liquid-air interface movement along the nucleus surface during the mechanical contact process, which results in transient high free energy conditions. Other hypotheses include the partial solubility of the ice nucleus in water (Fletcher, 1970; Guenadiev, 1970), and incomplete adsorption upon initial contact with water (Evans, 1970). In related work Czys (1989) presented an experiment in which the freezing of $3 \mathrm{~mm}$ drops was stimulated by a mechanical 
shock. Czys (1989) speculated that collision of supercooled drops in clouds might result in freezing, but the importance of the mechanism under atmospheric conditions remains uncertain (Czys and Lew, 1999). In recent studies Shaw et al. (2005) and Durant and Shaw (2005) investigated heterogeneous freezing induced by volcanic ash particles. Ash particles were immersed in water droplets and cycled through hundreds of freezing events. Ice nucleation occurred at higher temperatures if the ice nucleus was in contact with the surface of the drop, than if it was fully immersed within the drop. The contact freezing efficiency did not depend on whether surface contact was from the outside in, or the inside out. The experimental results appear to rule out most of the earlier proposed hypotheses for the contact freezing mechanism, since there was no transient contact event during the experiments and contact freezing was in operation during many freezing cycles. Suzuki et al. (2007a) used a high-speed camera to observe the freezing behavior of a water droplet on silicon surfaces treated with various silanes. Freezing was observed to preferably occur from the threephase solid-liquid-air contact line. The freezing temperature was also higher on a rough coating than on a smooth flouroalkylsilane coating (Suzuki et al., 2007b). Recently, Djikaev and Ruckenstein (2008) proposed a thermodynamic explanation how the three phase line energy could enhance the freezing efficiency.

The effect of humidity on freezing indicated in this study in the kaolinite-water system is not easily understood based on the current knowledge. The available experimental evidence from previous studies indicates that the existence of a solid-liquid-air interface strongly favor ice nucleation. The detailed surface properties of the solid particle may determine the onset temperature for contact freezing, but a number of different materials are able to induce contact freezing at a higher temperature compared to immersion freezing. The surface layer on water has somewhat different properties compared to the bulk. The mobility is higher and the density is somewhat lower. It is also likely that the surface layer more easily adapts to density changes when an ice phase is formed compared to the bulk. On its own, water does not appear to crystallize faster in the surface layer compared to in the bulk. A template is obviously required that can help the liquid to form an ice nucleus of sufficient size that may continue to grow. The template is related to the surface properties of the solid particle. One may speculate that the molecular level water-surface interactions are important, but confined spaces like pores and other surface features may play a role. The RH dependences in freezing efficiency indicated by this study is consistent with the mechanism proposed by Cooper (1974), since the formation of ice embryos from vapor phase onto the particles is enhanced by a high concentration of water molecules in the surrounding gas.

\section{Conclusions}

Freezing of supercooled water droplets induced by collisions with kaolinite dust particles has been studied in an EDB at temperatures from 240 to $268 \mathrm{~K}$. The relative humidity was observed to influence the freezing process. Under relatively dry conditions freezing occurred below $249 \mathrm{~K}$, while a freezing threshold of $267 \mathrm{~K}$ was observed when water vapor was inserted to the chamber, raising the relative humidity. The effect of relative humidity appears to be related to a direct influence on the contact freezing process itself, and it is not related to the lifetime of the droplets in the electrodynamic balance. Assuming that collisions at the lowest temperature employed had a probability of unity, one or a few collisions were usually sufficient to produce contact freezing within the whole temperature range. In clouds, the RH is close to $100 \%$. Hence, the data recorded with water vapor added is likely to be a more realistic case for atmospheric applications.

This limited study should be extended to improve our understanding of the process responsible for the contact freezing phenomenon. There is considerable room for improvement of the experiments. Experiments should in the next step be carried out with monodisperse aerosol particles, and the influence of droplet size should be evaluated. The effects of relative humidity should be quantified. Further improvements should also involve using fast cameras with micrometer resolution to directly observe the freezing efficiency in single particle-droplet collisions.

Acknowledgements. We gratefully acknowledge technical support by Benny Lönn. This work was supported by the Swedish Research Council, the Swiss National Foundation, the European Union through the SCOUT-O3 program, and the graduate school program Climate and Mobility at University of Gothenburg. Support from the Copenhagen Center for Atmospheric Research with founding from the Danish Natural Science Research Council and the Villum Kann Rasmussen Fund is acknowledged.

Edited by: D. Cziczo

\section{References}

Bailey, M. and Hallett, J.: Nucleation effects on the habit of vapour grown ice crystals from -18 to -42 degrees C, Q. J. Roy. Meteor. Soc., 128, 1461-1483, 2002.

von Blohn, N., Mitra, S., Diehl, K., and Borrmann, S.: The ice nucleating ability of pollen Part III: New laboratory studies in immersion and contact freezing modes including more pollen types, Atmos. Res., 78, 182-189, 2005.

Cantrell, W. and Heymsfield, A.: Production of ice in tropospheric clouds: A review, B. Am. Meteor. Soc., 86(6), 795-807, doi:10.1175/BAMS-86-6-795, 2005.

Cooper, A. W.: A possible Mechanism for Contact Nucleation, J. Atmos. Sci., 31, 1832-1837, 1974.

Czys, R. R.: Ice Initiation by Collision-Freezing in Warm-Based Cumuli, J. Appl. Meteorol., 28, 1098-1104, 1989. 
Czys, R. R. and Lew, J. K.: A wind tunnel investigation of interactions between supercooled precipitation-size water drops, J. Atmos. Sci., 56(17), 3079-3090, 1999.

Davis, E. J., Buehler, M. F., and Ward, T. L.: The double-ring electrodynamic balance for microparticle characterization, Rev. Sci. Instrum., 61, 1281-1288, 1990.

Diehl, K. and Mitra, S. K.: A laboratory study of the effects of a kerosene-burner exhaust on ice nucleation and the evaporation rate of ice crystals, Atmos. Environ., 32, 3145-3151, 1998.

Djikaev, Y. S. and Ruckenstein, E.: Thermodynamics of Heterogeneous Crystal Nucleation in Contact and Immersion Modes, J. Phys. Chem. A, 112, 11677-11687, 2008.

Drab, E., Gaudichet, A., Jaffrezo, J. L., and Colin, J. L.: Mineral particles content in recent snow at Summit (Greenland), Atmos. Env., 36, 5365-5376, 2002.

Duft, D. and Leisner, T.: Laboratory evidence for volumedominated nucleation of ice in supercooled water microdroplets, Atmos. Chem. Phys., 4, 1997-2000, 2004, http://www.atmos-chem-phys.net/4/1997/2004/.

Durant, A. J. and Shaw, R. A.: Evaporation freezing by contact nucleation inside-out, Geophys. Res. Lett. 32(20), L20814, doi:10.1029/2005GL024175, 2005.

Ettner, M., Mitra, S. K., and Borrmann, S.: Heterogeneous freezing of single sulfuric acid solution droplets: laboratory experiments utilizing an acoustic levitator, Atmos. Chem. Phys., 4, 1925-1932, 2004, http://www.atmos-chem-phys.net/4/1925/2004/.

Evans, L. F.: The role of the adsorbed layer in ice nucleation, Preprint Conf. Cloud Physics, Am. Meteor. Soc., Fort Collins, 1970.

Fletcher, N. H.: On contact nucleation, J. Atmos. Sci., 27, 10981099, 1970.

Fukuta, N.: A study of the Mechanism of Contact Ice Nucleation, J. Atmos. Sci., 32, 1597-1603, 1975.

Gibson, E. R., Gierlus, K. M., Hudson, P. K., and Grassian, V. H.: Generation of Internally Mixed Insoluble and Soluble Aerosol Particles to Investigate the Impact of Atmospheric Aging and Heterogeneous Processing on the CCN Activity of Mineral Dust Aerosol, Aerosol Sci. Tech., 41, 914-924, doi:10.1080/02786820701557222, 2007.

Guenadiev, N.: Sur le mécanisme de congélation des gouttes d'eau sous l'influence d'un aerosol d'iodure d'argent, J. Rech. Atmos., 4, 81-91, 1970.

Lohmann, U. and Diehl, K.: Sensitivity Studies of the Importance of Dust Ice Nuclei for the Indirect Aerosol Effect on Stratiform Mixed-Phase Clouds, J. Atmos. Sci, 63, 968-981, 2005.

Mason, B. J. and Maybank, J.: Ice-nucleating properties of some natural mineral dusts, Q. J. Roy. Meteor. Soc., 84, 235-241, 1958.

Matsumoto, M., Saito, S., and Ohmine, I.: Molecular dynamics simulation of the ice nucleation and growth process leading to water freezing, Nature, 416, 409-413, 2002.

Miller, J. D., Nalaskowski, J., Abdul, B. and Du, H.: Surface Characteristics of Kaolinite and Other Selected Two Layer Silicate Minerals, Canad. J. Chem. Eng., 85, 617-624, 2007.
Mishchenko, M. I., Travis, L. D., and Lacis, A. A.: Scattering, Absorption, and Emission of Light by Small Particles, Cambridge University Press, Cambridge, 2002.

Pitter, R. L. and Pruppacher, H. R.: A wind tunnel investigation of freezing of small water drops falling at terminal velocity in air, Q. J. Roy. Meteor. Soc., 99, 540-550, 1973.

Pruppacher, H. R. and Klett, J. D.: Microphysics of Clouds and Precipitation, Kluwer Academic Publishers, 2nd Ed., Dordrecht, The Netherlands, 347-355, 1998.

Roberts, P. and Hallett, J.: A laboratory study of ice nucleating properties of some mineral particulates, Q. J. Roy. Meteor. Soc., 94, 25-34, 1968.

Salam, A., Lohmann, U., Crenna, B., Lesins, G., Klages, P., Rogers, D., Irani, R., MacGillivray, A., and Coffin, M.: Ice Nucleation Studies of Mineral Dust Particles with a New Continuous Flow Diffusion Chamber, Aerosol Sci. Tech., 40, 134-143, doi:10.1080/02786820500444853, 2006.

Schaller, R. C. and Fukuta, N.: Ice nucleation by aerosol-particles Experimental studies using a wedge shape ice thermal-diffusion chamber, J. Atmos. Sci., 36, 1788-1802, 1979.

Shi, Z., Shao, L., Jones, T. P., and Lu, S.: Microscopy and mineralogy of airborne particles collected during severe dust storm episodes in Beijing, China, J. Geophys. Res., 110, D01303, doi:10.1029/2004JD005073, 2005.

Sigurbjörnsson, Ó. F. and Signorell, R.: Volume versus surface nucleation in freezing aerosols, Phys. Rev. E, 77, 051601, doi:10.1103/PhysRevE.77.051601, 2008.

Singer, A., Dultz, S., and Argaman, E.: Properties of the nonsoluble fractions of suspended dust over the Dead Sea, Atmos. Environ., 38, 1745-1753, 2004.

Shaw, R. A., Durant, A. J., and Mi, J.: Heterogeneous Surface Crystallization Observed in Undercooled Water, J. Phys. Chem. B, 109, 9865-9868, 2005.

Suzuki, S., Nakajima, A., Yoshida, N., Sakai, M., Hashimoto, A., Kameshima, Y., and Okada, K.: Freezing of water droplets on silicon surfaces coated with various silanes, Chem. Phys. Lett., 445, 37-41, 2007a.

Suzuki, S., Nakajima, A., Yoshida, N., Sakai, M., Hashimoto, A., Kameshima, Y., and Okada, K.: Hydrophobicity and Freezing of a Water Droplet on Fluoroalkylsilane Coatings with Different Roughnesses, Langmuir, 23, 8674-8677, 2007b.

Svensson, E. A., Badiei, S., Hallquist, M., and Pettersson, J. B. C.: Freezing of evaporating oxalic acid solution droplets, J. Phys. Chem. A, in review, 2009.

Tabazadeh, A., Djikaev, Y. S., Hamill, P., and Reiss, H.: Laboratory Evidence for Surface Nucleation of Solid Polar Stratospheric Cloud Particles, J. Phys. Chem. A, 106, 10238-10246, 2002a.

Tabazadeh, A., Djikaev, Y. S., and Reiss, H.: Surface crystallization of supercooled water in clouds, Proc. Natl. Acad. Sci. USA, 99, 15873-15878, 2002b. 